reactions:* (1) dissolution in concentrated sulphuric acid; a coloration ensues, which is generally change by the addition of water; (2) dissolution in water with the addition of a few drops of hydrochloric acid; ter, with the addition of soda; very often a colore precipitate is formed.

The combination of these three colored reactions is generally sufficient to detect the coloring matter. be obtained in the ash, in certain cases without chem ical change (smalts, ferric oxides, etc.). In other cases the original pigments will be in characteristic form while again the organic colorant will be difficult to distinguish, and the reactions must be determined on the paper itself.

vi. Determination of the RUPtURe Length and the LENGTHENING.

By "rupture length" is understood the length of strip of paper of any width and thickness, which under its own weight, and breaking at the point of suspension. This length is generally expressed in kilometers. There are several pieces of apparatus designed to determine the. rupture length, but all are constructed on the same principle; they are dynaemployed to subject the strip of paper to traction. The most convenient dimensions for this strip have been found to be 0.015 meter in width and 0.18 meter in length. This band is held at each extremity by a clamp and the two clamps are separated from each other by means varying according to the kind of apundergoes traction, and when this is sufficient, the paper breaks. A hand fixed to the apparatus gives the increase in the separation of the clamps.

The rupture length is now to be calculated. Sup pose that the test has shown that the average weigh of a strip of paper of 18 centimeters is $p$; we must, according to the definition of the rupture length, calculate what length of the strip of paper of the same
width is equivalent to a weight $P$ (rupture load). Let $x$ be this length; we have $\frac{0.18}{p}=\frac{x}{P}$; whence $x=\frac{0.18}{p} \times P . \frac{0.18}{p}$ is called the number oof the strength of a paper.

The result $x$ allows of comparing all papers togethe of the width and thickness of the sample.

$$
\text { RESISTANCE TO RUMPLING. }
$$

There is at present no apparatus for making the rumpling test; this must depend on the operator. and is ordinarily thus conducted: Half a sheet of the paper
to be tested is first reduced to a ball, then spread out to be tested is first reduced to a ball, then spread out papers of quite inferior resistance will quickly exhibit papers of quite inferior resistance will quickly exhibit rumpling may be expressed as extraordinarily small. The folded paper is afterward taken with both hands and rubbed smartly, as a washerwoman rubs linen in rinsing it. After some practice it is not diffcult to class papers in a series of seven types, from
that of extraordinarily great resistance to that of exthat of extraordinarily reat resistance to that of ex-
iraordinarily slight resistance. The attempt has also been made to determine the loss of resistance by folding, but as this result gives the same value for very different papers, 'no sufficient substitute has been adopted for the rumpling test.

Such is approximately the point which has so far been reached in the testing of papers; it is probable that chemical analysis, and especially microscopic
examination, has surprises in store for us, with referexamination, has surprises in store for us, with refer-
ence to the method by which papers have been manu-
factured. Observations of this kind will throw light upon certain points now obscure and afford an explanation of certain phenomena whose causes now elude us.

\section{THE CONTAL NUT WRENCH.}

THE tool represented herewith is designed for the use of automobilists, who of ten have occasion to loosen used in the construction of a carriage. The essential art of this wrench is a steel tube forming a tool carrier.
Within the end of the tube is a square hole that may be used for turning nuts of that size directly, or for receiv- the tool is furnished a set of blanks corresponding to various sizes of nuts and bolts that are likely to straight squared rore may also be used, insere compla cated consisting of two rods united by a universa
joint, so as to render it possible to loosen or tighten

perations in some of the districts even near the rail the logs over comparatively short stretches of coun try. To invent a motor that would obviate this difficulty
has been the study of Mr. A. O. Lombard, of Water-

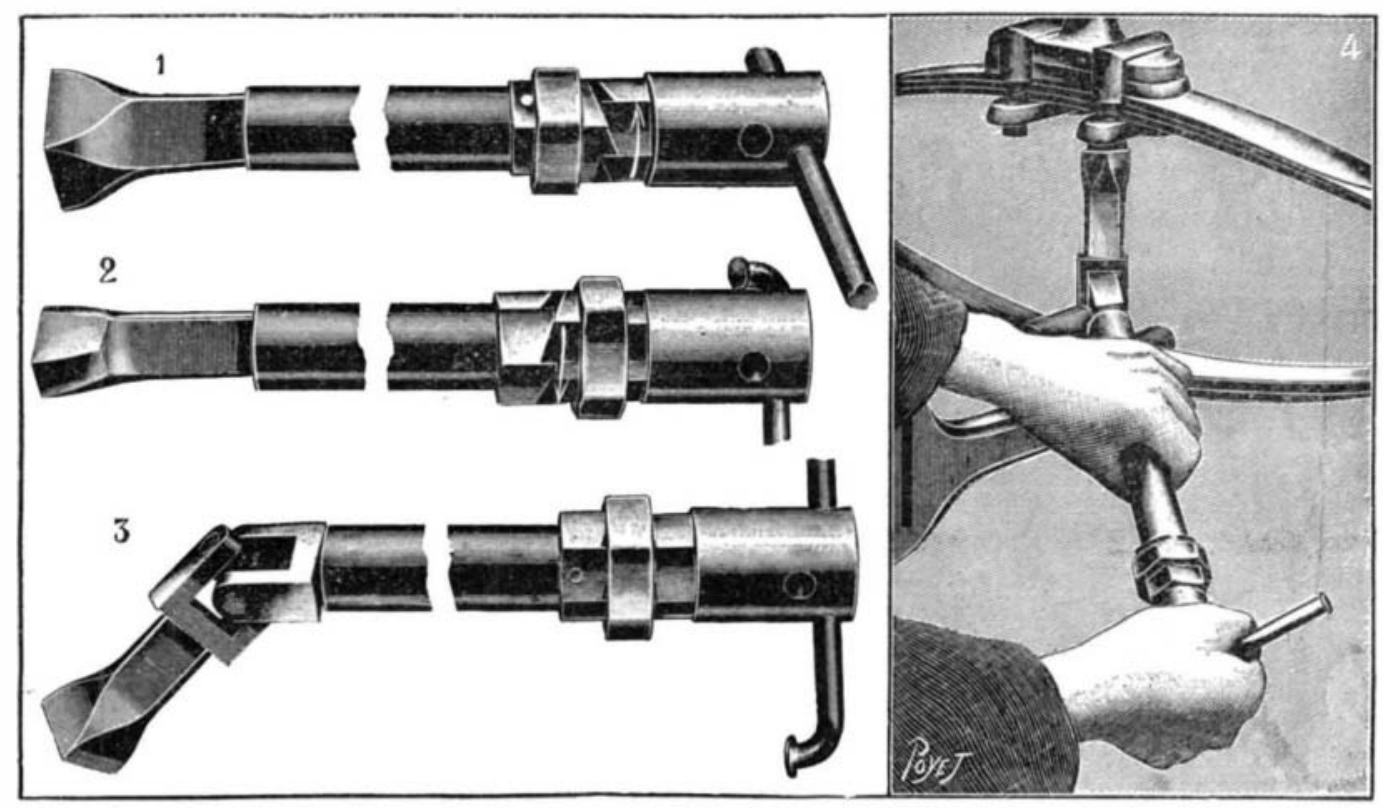

THE CONTAL AUTOMOBILE WRENCH. nuts that are located in places that are not easily accessible. One of the ingenious features of this tool is a ratchet arrangement that permits of revolving the tool carrier
either from left to right, or from right to left. Externally to the tool carrier and on the end opposite that having the hole, is mounted a ratchet collar, the clutch of which mesh with those of a loose ing a washer which forms a bearing for a spiral spring placed between the collar and the end of the tool carrier and abutting at the other extremity against a shoulder formed upon the carrier. In order to obtain
the ratchet control of the tool carrier. it became necesthe ratchet control of the tool carrier, it became neces-
sary to find a combination that should assure the interdependence of one or the other of the two sets of teeth. This object has been attained in the simplest manner. Around the tooth slides a coupling ring provided with ally upon the corresponding periphery of the clutch collar, sleeve, and ratchet collar. This ring has a carefully calculated width, so that it may, through displacement, operatively connect the clutch collar with the ratchet
collar, with the collar forming the head of the tool, or with both simultaneously. In the first two cases we key forms but a key forms but a single piece and plays the part of an
ordinary fork-wrench. It is hardly necessary to say that the tool is provided at the extremity with a lever, which is placed in a position at right angles with the axis of the wrench when it is desired to make use of
the latter, and parallel with it when the tool is to be the latter, and parallel with it when the tool is to be
placed in its case. This rod, which is of steel, is bent at the extremity, and kept flat near the bend. When passes into the head of the tool, its flattened portion comes perpendicular with a slit that prolongs one of the apertures. This permits of pulling out one of the ends of the lever and making it describe a semicircle,
and then a quarter-circle until it finally rests against and then a quarter-circle until it finally rests against
the tool, where it is held by a flange at the end of its curved extremity.-Translated from

\section{LOG-HAULING MOTORS.*}

By Day Allen Willey.

A мотов designed specially for transporting lumber and $\log$ over the rough roads and even cross country
in the Maine woods has been the object of much in-
terest among the lumbermen in this section of the ville, Me., for several years. Mr. Lombard and his are familiar with the conditions in the machinery, and As the result of the experiments, Mr. Lombard built a machine at his Waterville factory, which has already been used during one winter with quite satisfactory hauler, and it may be aid to lay its own a stem log hauler, and it may be said to lay its own roadbed autoway or field. It consists of a steam engine and boiler mounted on a framework of heavy beams. The front portion rests on a pair of sledge runners connected with the cab by chains, which turn the runners from side to side as the front wheels of an automobile are con trolled. In fact, the chains form the steering gear. a small locomotive rest upon a lag bed, which is on of the remarkable features of the invention it is and $8 \frac{1}{2}$ inches wide. The sections are joined by metal hinges, which permit the bed to pass around two sprocket wheels, each 3 feet in diameter. The sprockets are placed on axles and are 5 feet apart. On each section of the lag bed or lag is what the inventor calls a toe calk, similar to the point on a horseshoe, but as it prevents the bed from slipping when the motor is moving.

The cylinders, as will be noted in the illustration are located beneath the boiler, and are attached in such a way that the power is communicated directly to the sprocket or driving wheels. The machine is controlled by valves and levers as on an ordinary locolag bed is sufficient put in motion, the length of the lag bed is sufficient to allow it to move $5 \frac{1}{2}$ feet, when
another section of equal length is laid down by the wheels, which, as the engine moves forward, pick up
the "slack" or the portion on which it has been traveling. To use an ordinary illustration, the lag bed might be compared to a plank thrown on the ground as a foundation for the wheels of a vehicle, and taken up after it

A series of ball bearings keep the lag bed true, pressions and drifts. The runner, such as slight deattached in such a manner that it adjusts itself to the contour of the surface without difficulty. Although the "Forest Echo," as this novel locomotive is termed, weighs 14 tons, the plan for furnishing it a movable

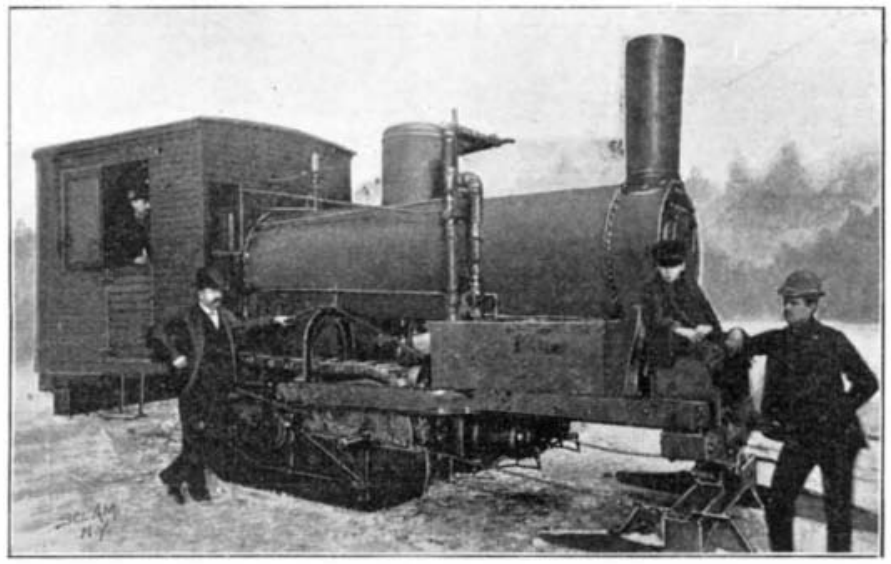

STEAM LOG HAULER.

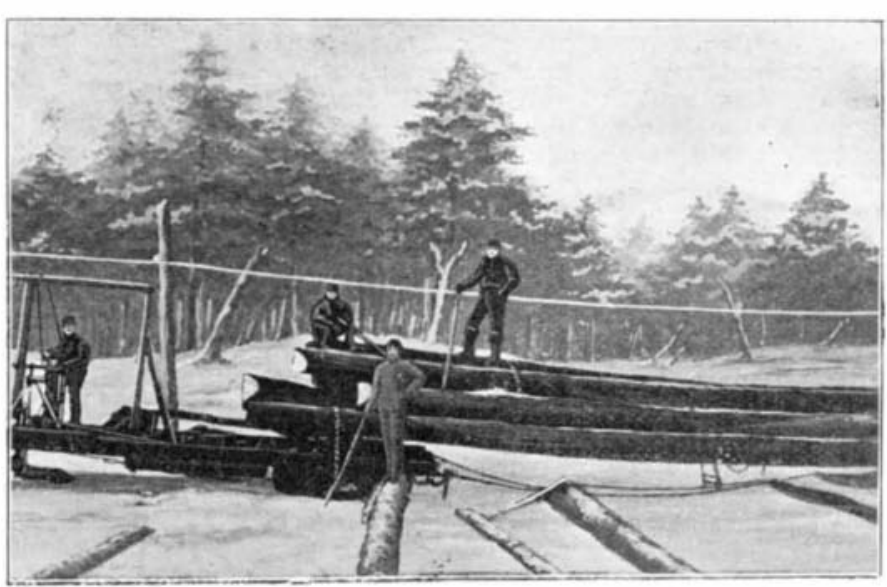

ELECTRIC LOG HAULER.
Ing other pieces of steel tubing having in one end a
square aperture corresponding exactly to the dimensions of a bolt or nut, and, on the other, a squared end
to fit in the hole that terminates the tool carrier. With

* If the colorant is insoluble in water, the attempt should be made to
diseolve it in alcohol. country, owing to its novel features. The severe win-
ters are attended with heavy snowstorms, which frequently make the highways impassable for ordinar drifts. The timbermen have been obliged to suspend the snowy surface without sinking. On an ordinary road it will attain a speed of four miles an hour, drawing four sledges with 17,000 feet of logs. It has also been used for hauling snow plows to open roads
in the lumber districts, pulling the plow through drifts which had "stalled" a string of 24 horses. 
bard has been working with an electric trolley hauler of his own design, with successful results. A power Dead River, and here sufficient current was generated in the aggregate. The necessary feed wires were in stalled on a mountain road about seven miles in length. where the grade is too steep to admit operating the
steam hauler. The motors were placed on a platform, one in front and one in the rear, so they can be controlled singly or together as desired. A sledge run ner was fastened under the front part of the platform, line, being connected by an iron rod with a wheel course applied to the sprockets or drivers, in the same
manner as it is applied to the trucks of an ordinary manner as it is applied to the trucks of an ordinary sprockets are arranged in the manner already de-
scribed. It has the advantage of being much lighter scribed. It has the advantage of being much lighter
in weight, as the boiler and firebox are not required. in weight, as the boiler and firebox are not required.
It was tested last winter, hauling loads equal to those pulled by the "Forest Echo" up twice the percentage

The log haulers are considered so practical that the operated by steam power, which will be employed by a lumber company on Alder Creek for getting all of its logs from the woods to its mills. This type has
made trips of 25 miles, carrying loads, without being
"stalled"

FIRE APPLIANCES AT THE EXHIBITION OF GERMAN CITIES IN DRESDEN.

THE great progress in the domain of fire appliances and me Exhibition of conflagrations is clearly shown automobile, much maligned on account of excesses com mitted by sportsmen, is doing excellent service in this field.

The city of Hanover exhibited- the models of its automobile fire train, consisting of steam fire engine,
gas fire engine, and a cart carrying a hydrant water

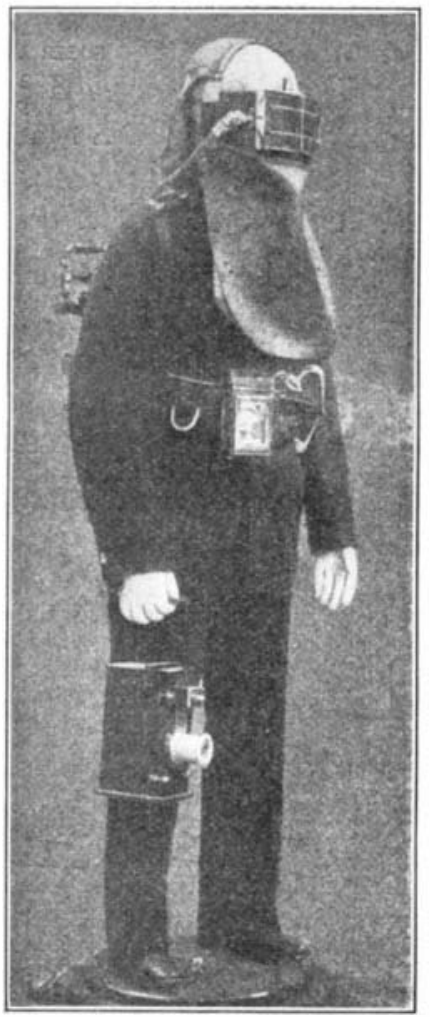

MODEL OF A FIREMAN WITH GIESBERG OXYGEN APPARATUS.

post or fire hook contrivance for connecting a nozzle Hanover is th hose to the water main in the street. mobile fire train. This considerably reduces the run-
mons ning expenses, as horses are no longer required. The fire engine house of the exhibition, by the way, is equipped with.a real automobile fire train, which is served by the crew of the Dresden fire department, and formerly Busch, of Bautzen. The train consists of an automobile steam fire engine, an automobile crew-
wagon, and an automobile ambulance. The steam of the engine drives during the trip a starting machine, and, while fighting the fire, a steam pump. With an adater are supplied per minute.

Besides the automobile fire train, the Bautzen firm also exhibits at the fire engine house of the exposition lader, constructed by the firm of Fries Sohn, of Frankfort a. M. By nieans of compressed air or carbonic acid, which is kept in a steel receptacle, the four tele-
scoping tubes are forced up. The different parts of the scoping tubes are forced up. The different parts of the latter are attached to the upper extremities; each tube
portion, when forced up, carries along its portion of the portion, when forced up, carries along its portion of the
ladder. In the hands of a well-drilled fire brigade, the ladder. In the hands of a well-drilled fire brigade, the
ladder, four stories high, is made ready for use in twenty to thirty seconds. The pressure of about ten atmospheres is sufficient to send up a fireman and hose without delay. The whole ladder with truck is made of iron. It may be moved with the support in a circular direction, like a revolving crane, without
having to turn the truck at the same time. To all these advantages must be added still another, viz., that it can be manipulated by two men, while four men are generally required to operate a mechanical ladder.
The city of Leipsic has exhibited excellent pictures of fire stations, which must be called model in every automatically. When the alarm comes in, the station is notified by the device without the co-operation of the telegrapher. At the same time, the time-stamp clock records automatically the exact time when the model of a fireman fully equipped and provided with a Giesbers present an illustration of the same, and for comparison, one of a model with fireproof suit exhibited by the city of Kiel. Besides his fire-resisting suit, the Kiel fireman is wearing a protective mask over his head. The air to breathe is conveyed to him by means of a hose from the atmosphere. The Leipsic fireman, however, carries the air with him in a compressed state,
so that he can move about freely and independent of an air hose and of the outside. The oxygen reaches his halations and the superfluous oxygen go into the bag
on the chest, where they are sucked up by an injector and conveyed into a regenerating drum. There the alkali absorbs the exhaled carbonic acid, thus rendering them. A man equipped in this manner can remain for two hours in a room filled with smoke or gas:

Of the other exhibits in fire appliatrces we may mann and Herrmann of Dresden, exhibited an artificial short circuit for strong current lines of electrio street cars, by means of which the current in a trolley wire may be quickly interrupted without danger, if it
hinders the firemen in their work. Furthermore, there

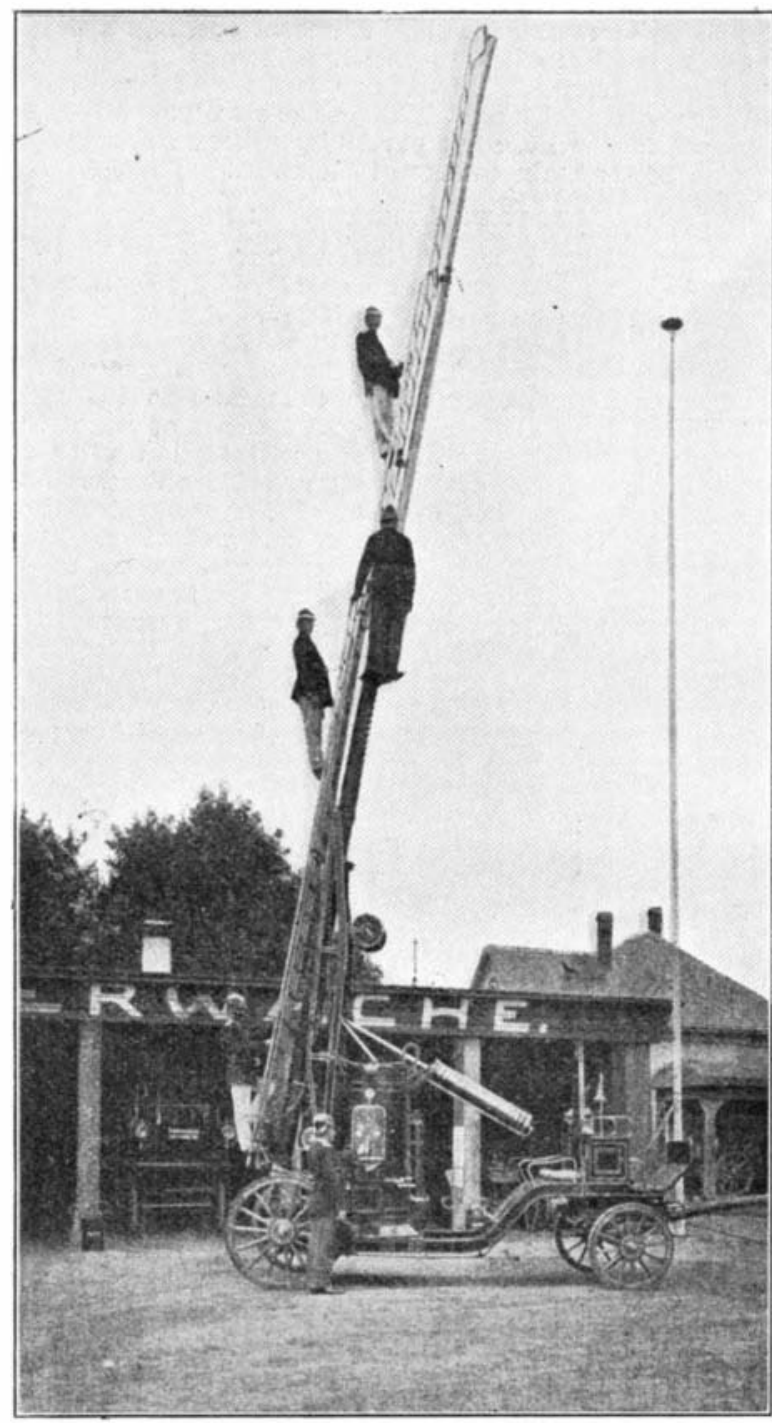

MECHANICAL TOWER UR REVOLUBLE SLIDING LADDER.

was exhibited a plan of the telegraph and fire alarm net-work system of the city of Dresden, with a stationary and wall alarm. The Dresden firm of A. G. Handel showed a novel dismountable fire engine which
can be used on wheels as well as on sleigh runners, can be used on wheels as well as on sleigh runners, and possesses great mobility. Berlin put on exhibition fire train, while Bremen sent very fine models of a fireboat (for seaports) and a gas fire engine. From trivance, by means of which the ventilators in city theaters open at once automatically, when the iron curtain is let down in case of a fire; also a sliding. cloth which can be used both for jumping and sliding. Chemnitz exhibited a rain contrivance for the protection of the wood construction of a church steeple; also Finally, there was on exhibition, from Kiel, the excelFinally, there was on exhibition, from Kiel, the exce nigsberg, a combined fire alarm and accident call.

The exhibits comprising the department for extinguishing fires are so varied and numerous that they
afford a perfect survey of the highly developed fire departments of Germany.- Translated for the ScIEN-
TIFIC AMERICAN SuppLEMENT from Illustrirte Zeitung. THE GERMAN TOWNS EXHIBITION AT DRESDEN. LitrLe notice has been taken, says a correspondent of the Manchester Guardian, of the German Towns Exhibition which has been open in Dresden during the summer. The Germans take the development of their towns seriously. As in England, though to a less extent, the population is more and more concentrating in the large towns, creating problems of administrathe attention of the best intellects available. In Germany the service of the town is regarded as in the highest degree honorable. There is a highly-traine cases elected to the position, but giving their whole time to the work and receiving salaries. There are, in among whom are to be found prominent business and professional men. state of German towns at the beginning of the twentieth century, and to give those interested an oppormunicipal services. The chief organizer was the Oberbürgermeister of Dresden, Herr Bentler, assisted by a committee which includes the officials of the chief under the control of a special committee of experts in under the control of a special committee of experts in all German towns, and exhibits have been sent by 128 of varying size and importance. Firms and companies which contract for municipal services or supplies were also offered space for exhibits, and they are well rep-
resented in a special pavilion and in separate buildresented in a special pavilion and in separate build-
ings in the grounds. The main exhibition has eight ings in the grounds. The main exhibition has eight
sections: (1) Town engineering (street construction, bridges, harbors, waterways, etc.) ; (2) Town Extensions, Building Regulations and Housing; (3) Public Art; (4) Public Health, Police; (5) School Organiza-
tion, including education for those beyond school age; (6) Poor Relief, Care of the Sick, Charitable Instituings banks: (8) Registration and Official Books, Paings banks; (8) Registration and Official Books, Pa-
pers and Appliances, Statistics and Literature. There are, in addition, three separate exhibitions-the trades exhibition and an electrical undertaking exhibition. in a brief article deal with exhibition. tions which deserve attention. I may, however, refer
particularly to the sections dealing with streets and with town extension and housing. The continental mind, perhaps from a subtle military influence, seems more awake to the need for wide, well-made streets in
towns, both from considerations of transit and of pubwhen Baron Haussmann drove straight lines of communication through Paris, there has been an evident a similar way. But the straightness of the street is

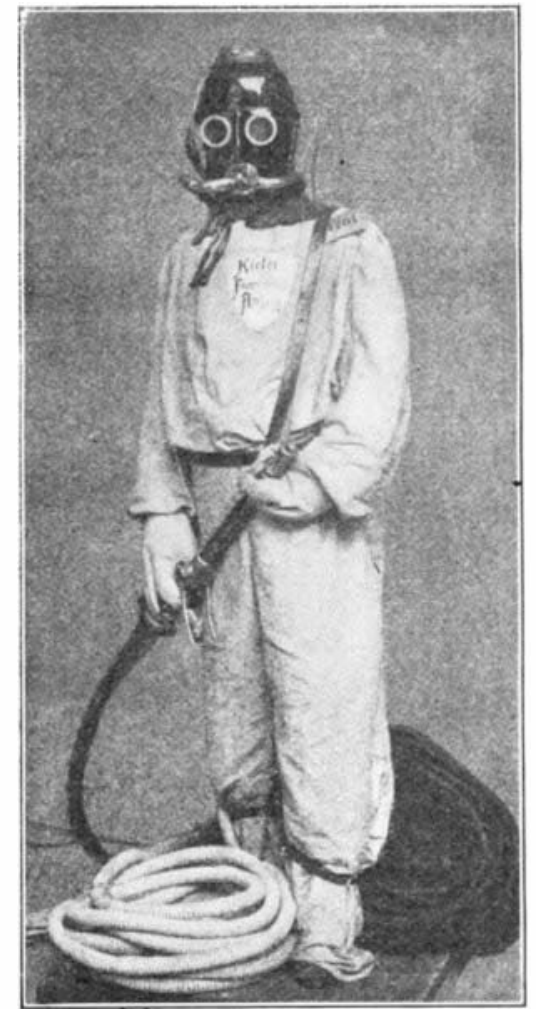

MODEL OF A FIREMAN'S SUIT OF THE KIEL FIRE DEPARTMENT.

not everything, by any means. It has to be wide enough for its traffic, and possibly different kinds of traffic will have to be provided for in one street. If creased, trees must be planted, and advantage should be taken of natural or artificial perspectives. The surface should not only be able to bear the traffic, but Finally, it is along the street lines that the drainge water, gas and electric-supply system run, and a wellorganized town will arrange these so that access can be had to them without disturbing the street. Such are some of the matters which the street engineer has
to consider. There are here numerous diagrams showing streets in plan and section, often with photographs and models. In the exhibition grounds on terial, and there are also actual street sections to show the arrangement of underground works. Apparently wide streets are to be the rule in German town Judging from the exhibits, the whole tendency is in this direction. Separate tracks for slow traffic and for
fast traffic, for foot passengers, for cyclists, and for riders are being constructed in several towns. growth of a town and to make provision beforehand for the streets that will be required. Perhaps nothing in the exhibition is more interesting than the plans (many of which are large-scale relief models) of the are not yet made. The officials of the chief towns hav profited from their past diffculties, and now insist that their towns shall grow on scientife principles. In some cases the municipalities are themselves build In some cases the municipalities are themselves buildthe assistance of public funds and under the supervision of the town councils, are the main agents in
supplying the needs of the community. The build- 